\title{
THE COMPLICATIONS OF CSOM : OUR EXPERIENCE
}

Authors: Anitya Srivastava (1), Ashish Chandra Agarwal (2)

Authors affiliations: (1)Senior Resident, (2) Associate Professor, Department of ENT, Dr. Ram Manohar Lohia Institute of Medical Sciences, Lucknow, India.

\begin{abstract}
Context: Chronic Suppurative Otitis Media (CSOM) is a commonly encountered middle ear disease resulting in morbid complications and squeals. It is broadly classified into safe and unsafe type; in which unsafe CSOM is commonly associated with complications due to the bone erosion effect of cholesteatoma and super added infections. The rise in antibiotic use has reduced the incidence of complications but the current practice of unscientific administration of antimicrobial agents has made the microbiome resistant, ironically increasing the rate of certain complications. Aim: This study was conducted to profile the complications in unsafe CSOM. Material and Methods: A record based cross sectional study was conducted between January 2015 and October 2018 on 241 cases of unsafe CSOM at a tertiary care hospital in North India. Results: Out of 241 cases 14\% presented with complications. Of these $76.6 \%$ had extra cranial complication and $23.33 \%$ had intracranial complications. Conclusion: Mastoid abscess and meningitis were the most frequently encountered extra and intra cranial complications respectively. Judicious use of antibiotics will go a long way in reducing the morbidity due to the disease.
\end{abstract}

Keywords: CSOM; Extra cranial complications; Intra cranial complications.

\section{Introduction}

CSOM has been a common cause of middle ear disease since prehistoric times ${ }^{[1]}$ and is characterized by a long standing inflammation of the middle ear cleft. It is important to differentiate between the two types of CSOM viz. the safe and unsafe types; because unsafe type is commonly associated with life threatening complications ${ }^{[2]}$.

The rise in the use of antibiotics began in 1940s, and it has dramatically reduced the incidence of infective complications ${ }^{[3]}$. Due to unscientific use of antibiotics, many micro organisms have developed multi drug resistance, making antibiotics less effective and complications more common ${ }^{[4]}$. A large scale research is required to assess the current trend of complications in order to reduce the morbidity and mortality secondary to the disease.

\section{Material and Methods}

A record based cross sectional study was conducted in the department of ENT of a tertiary care hospital in north India, with an aim to profile the complications of unsafe CSOM. The duration of the study was 4 years and 9 months (January 2015 to October 2018). 241 cases diagnosed to have unsafe CSOM were included in the study. Patients having congenital ear diseases, malignancy of the ear, history of radiation to the head and neck region, diagnosed cases of tuberculosis and those having past history of taking anti tubercular therapy were excluded from the study.

Patient's data was recorded using retrospective charts review data collection method based on the articulated aims of the study. The data was analyzed using Microsoft Excel and SPSS version 20 statistical software. Descriptive statistics were used. Appropriate parametric and non parametric tests were applied to assess the association between various variables and were expressed in percentage. 


\section{Results and observations}

241 cases were studied during the study period and the age of the cases was between 9 years and 60 years. There were 114 males (47.3\%) and 127 females (52.69\%). 70 cases had bilateral ear disease (29.04\%), 80 cases had right ear disease (33.19\%) and 91 cases had left ear disease (37.75\%) [Table I].

Table I: Laterality of the involved ear.

\begin{tabular}{|l|l|l|}
\hline Right ear & 80 & $33.19 \%$ \\
\hline Left ear & 91 & $37.75 \%$ \\
\hline Both Ears & 70 & $29.04 \%$ \\
\hline
\end{tabular}

Amongst all the cases, $88 \%$ were without complications and $12 \%$ had complications [Figure I a]. Among those who presented with complications; 23 cases $(76.66 \%)$ had extracranial complications and 7 cases (23.33\%) had intracranial complications [Figure I b].

Figure la: Percentage of patients of unsafe CSOM presenting with complications.

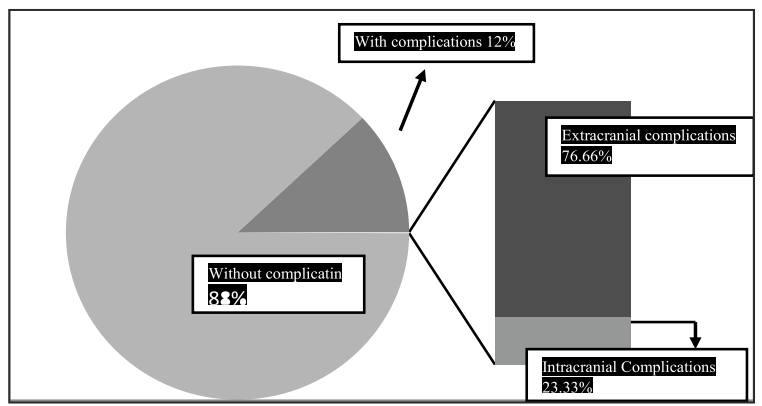

Figure Ib: Rate of different complications.

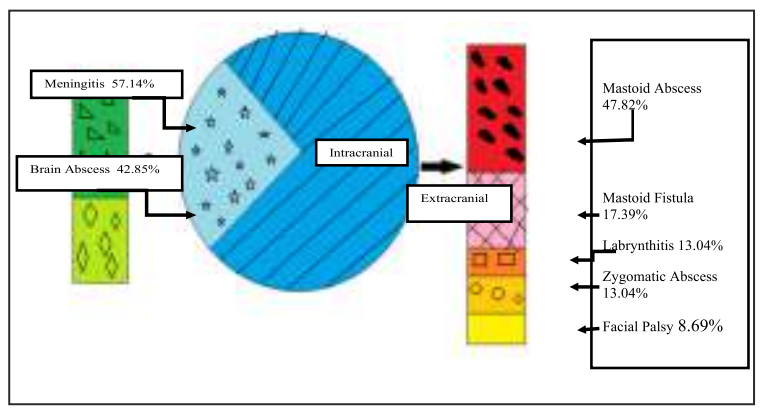

From figure I b, it can be noted that mastoid abscess was the most common extracranial complication and this was followed by a mastoid fistula, labrynthitis, zygomatic abscess and facial palsy. Meningitis was the most common intracranial complication and this was followed by a brain abscess.

\section{Discussion}

CSOM is common middle ear pathology and the unsafe type is frequently associated with complications. Presence of cholesteatoma along with a superadded bacterial infection results in the destruction of the bone and this leads to complications. Hematogenous spread of the pathology has also been documented ${ }^{[5]}$. Though the use of antibiotics has reduced the frequency and severity of complications, yet these are still encountered, probably due to the unscientific usage of anti microbial agents.

In our study, the male: female ratio was 1:1.1 and this was similar to some studies ${ }^{[1,6]}$ which have been done in the past. A study by Poursadegh et al ${ }^{[7]}$ reported male to female ratio of 1.39:1. A gender inequality can be an incidental finding as there is no knowledge of any anatomical difference in the structure of ear of males and females.

In our study, the age of the youngest patient was 9 years and oldest 60 years, the mean age was 26.8 years. 86 cases were between the age group of 20-30 years. Acquired cholesteatoma is commonly seen in patients less than 30 years of age ${ }^{[8]}$. Majority of the cases in our study had unilateral involvement and this was similar to a report by Boruah $D^{[8]}$. In a study by Goma et al ${ }^{[9]}$, bilateral involvement was noted predominantly.

In this study extracranial complications were more commonly encountered. Mastoid abscess was the most common amongst them, followed by a mastoid fistula. A study conducted by Sharma and Jaiswal et al $\left.{ }^{[10}\right]$ also had a similar results. This finding has also been supported by studies conducted by Wanna GB et al ${ }^{[3]}$, Viswanatha B et al ${ }^{[4]}$, Thappa $\mathrm{N}$ et al ${ }^{[11]}$. 
The present study had intracranial complications in 7 patients of unsafe CSOM. The majority had meningitis and this was followed by brain abscess. In a study by Thappa et al ${ }^{[1]}$ with 699 patients, brain abscess was reported as the most common complication. In our study, all the cases of brain abscess had temporal lobe involvement, which was at par with the results of J Samuel ${ }^{[12]}$ whereas according to studies done by Murthy et al and Dubey et al, abscess secondary to an otogenic infection was more frequent in the cerebellum ${ }^{[13,14]}$.

The incidence of intracranial and extracranial complications has decreased due to the administration of antibiotics. Yet, it is not uncommon to come across patients having extension of infection beyond the confines of the middle ear cleft, particularly in the developing world. The reasons could be multiple viz. poor personal hygiene and unawareness of the disease, inadequate health care facilities, unscientific usage of antibiotics and the presence of co-morbidities. An awareness about the disease, proper clinical evaluation, appropriate investigations, prescription of antibiotics as per culture sensitivity reports and surgical intervention at the earliest will ameliorate the morbidity associated with this condition.

\section{Conclusion}

Awareness at the level of community, state of the art health care facilities, judicious use of antibiotics and a good post treatment follow- up will go a long way in preventing the complications of CSOM.

\section{References}

1. Aljehani M, Alhussini R. The Correlation between Preoperative findings of High Resolution (HRCT) and Intraoperative findings of Chronic Otitis Media (COM). Clin Med Insights Ear Nose, throat. 2019;
12:50-55.

2. RaiT. Radiological Study of the temporal bone in chronic otitis media: Prospective study of 50 cases. Indian J Otol. 2014; 20:48-55.

3. Wanna GB, Dharamsi LM, Moss JR, Bennett ML, Thompson RC, Haynes DS. Contemporary management of intracranial complications of otitis media. Otol Neurotol. 2010;31:111-117.

4. Viswanatha B, Sarojamma, Vijayashree MS, Sumatha D. Unilateral attico antral ear disease with bilateral intracranial complications. Indian J Otolaryngol Head Neck Surg. 2012;64(1):82-86.

5. Mittal R, Lisi CV, Gerring R. Current concepts in pathogenesis and treatment of chronic suppurative otitis media. J Med Microbiol 2015;64:1103116.

6. O'Donoghue GM, Bates GJ, Anslow P, Rothera MP. The predictive value of High Resolution Computerized Tomography in Chronic Suppurative ear disease. Clin Otolaryngol Allied Sci. 1987; 12:89-96.

7. Poursadegh $M$, Hashemi $G$, Jalali $M$. Evaluation of anatomical variations of vestibular aqueduct dimensions in temporal bone CT scan. Med J Islam RepubIran. 2000; 14:199-202.

8. Boruah D, Sharma KB, Sanyal S et al. Role of HRCT in the evaluation of suppurative disease of middle ear and mastoid and there complication with surgical correlation. J Evolution Med. Dent. Sci. 2016;5:850-858.

9. Gomaa MA, Abdel Karim AR, Abdel Ghany HS, Elhiny AA, Sadek AA. Evaluation of temporal bone cholesteatoma and the correlation between High Resolution Computed 
Tomography and surgical finding. Clin Med Insights Ear Nose Throat. 2013;6:21-28.

10. Sharma N, Jaiswal AA, Banerjee PK, Garg AK. Complications of chronic suppurative otitis media and their management: A single institution 12 years experience. Indian J otolaryngol head neck surg 2015;67(4):353-360.

11. Thappa N, Srivatsva RP. Intracranial complication of CSOM, atticoantral type: experience at TUTH. J Neuroscience 2004; 1:36-39.

12. Samuel J, Fernandes CM, Steinberg JL. Intracranial otogenic complications: a persisting problem. Laryngoscope. 1986;96:272-278.

13. Murthy PS, Sukumar R, Hazarika P, Rao AD, Mukulchand, Raja A. Otogenic brain abscess in childhood. Int J Pediatr Otorhinolaryngol. 1991;22:9-17.

14. Dubey SP, Larawin V. Complications of chronic suppurative otitis media and their management. Laryngoscope. 2007;117:264-267.

\section{Source of support: Nil.}

\section{Acknowledgement: None}

Conflict of interest: None declared. The manuscript has been read and approved by all the authors, the requirements of authorship have been met and each author believes that the manuscript represents honest work.

\section{*Corresponding author:}

Ashish Chandra Agarwal MS (ENT), MRCS Ed

Assistant Professor, Department of ENT, Dr. Ram Manohar Lohia Institute of Medical Sciences, Lucknow, India

Email:ashishchandraagarwal@gmail.com 